\title{
Chronic Benzodiazepine Administration XI. Concurrent Administration of PK11195 Attenuates Lorazepam Discontinuation Effects
}

John J. Byrnes, B.A., Lawrence G. Miller, M.D., Karen Perkins, M.D., David J. Greenblatt, M.D., and Richard I. Shader, M.D.

Berzodiazepine discontinuation is associated with alterations in motor activity and gamma-aminobutyric aid-A receptor upregulation in a mouse model. Prior studies indicate that concurrent administration of the compound N-methyl-N-(methyl-1-propyl)chloro-2-phenyl1-isoquinoline-3-carboxamide (PK1195), a "peripheral" site benzodiazepine antagonist, can attenuate the effects of lomepam on tolerance and receptor alterations. To coluate the effects of PK11195 administration on nzodiazepine discontinuation, we administered lomeepam (2 mg/kg per day), PK 11195 (1 to $10 \mathrm{mg} / \mathrm{kg}$ per day) or the combination to mice for 7 days, and then caluated pentylenetetrazole-induced seizure threshold and benzodiazepine binding at days 1, 4, and 7 after discontinuation. Seizure theshold was reduced at 4 days after lorazepam discontinuation; this effect was attenuated by coadministration of PK11195 at $5 \mathrm{mg} / \mathrm{kg}$ per day. Lorazepam discontinuation effects were not altered by PK11195 at $1 \mathrm{mg} / \mathrm{kg}$ per day, whereas the 10-mg/kg dose was not different from $5 \mathrm{mg} / \mathrm{kg}$ per day. The competitive ligand Ro5-4864 at $10 \mathrm{mg} / \mathrm{kg}$ per day, blocked the effects of PK11195 on lorazepam discontinuation. Benzodiazepine receptor binding in vivo was increased in the cortex and hippocampus at 4 days postlorazepam discontinuation. This effect was attenuated in the hippocampus but not in the cortex by concurrent administration of PK1195. These data indicate that concurrent administration of PK11195 may attenuate discontinuation effects of lorazepam. [Neuropsychopharmacology 8:267-273, 1993]
KFY WORDS: Lorazepam; PK11195; Benzodiazepine; Comma-aminobutyric acid

The abrupt discontinuation of benzodiazepine compounds may evoke a variety of discontinuation syndromes, characterized by anxiety, insomnia, and in rare

From the Departments of Pharmacology and Experimental Therapeutics and Psychiatry, Tufts University School of Medicine; and the Division of Clinical Pharmacology, New England Medical Center, Boston, Massachusetts.

Address correspondence to: Dr. Lawrence G. Miller, Box 1007, New England Medical Center, 750 Washington Street, Boston, Massachusetts 02111.

Received June 18, 1992; revised October 21, 1992; accepted October \. 1992. cases even seizures and mortality (Greenblatt et al. 1990). We have previously described a mouse model of benzodiazepine discontinuation that demonstrates both behavioral and neurochemical alterations (Miller et al. 1988b). In particular, hyperactivity and a reduced seizure threshold are associated with upregulation at the gamma-aminobutyric acid-A $\left(G A B A_{A}\right)$ receptor complex. Generally similar results have been obtained with the benzodiazepines lorazepam, alprazolam, and clonazepam (Lopez et al. 1990; Galpern et al. 1990, 1991a).

Several interventions have been proposed to prevent or limit the effects of benzodiazepine discontinuation, including tapering doses, use of "partial agonist" benzodiazepines, and treatment with anticonvulsants 
or benzodiazepine antagonists (Miller et al. 1992). In the mouse model, treatment with the anticonvulsant carbamazepine attenuates the effects of alprazolam discontinuation (Galpern et al. 1991b). We have recently reported that administration of the "peripheral" benzodiazepine antagonist $\mathrm{N}$-methyl- $\mathrm{N}$-(methyl-1propyl)chloro-2-phenyl-1-isoquinoline-3-carboxamide (PK11195) limits the development of tolerance to lorazepam (Miller et al. 1992), as was previously reported in a model of diazepam tolerance in the rat (Massotti et al. 1990).

In view of the postulated relationship between tolerance and withdrawal, the present study was designed to evaluate the effects of chronic administration of PK11195 on benzodiazepine discontinuation in the mouse model. Mice received chronic lorazepam, with or without PK11195 or the competitive ligand Ro5-4864, for 1 week, and then induced seizure thresholds and benzodiazepine binding were evaluated.

\section{METHODS}

\section{Materials}

Male CD1 mice, 6 to 8 weeks of age (Charles River, Wilmington, MA) were maintained on a 12 -hour light/dark cycle and given food and water ad libitum. Osmotic pumps were obtained from Alza (Palo Alto, CA). PEG 400 was obtained from J.T. Baker (St. Louis, MO). $\left[{ }^{3} \mathrm{H}\right]$ flunitrazepam (specific activity $70 \mathrm{Ci} / \mathrm{mmol}$ ), [ $\left.{ }^{3} \mathrm{H}\right]$ Ro15-1788 (flumazenil; specific activity $81 \mathrm{Ci} /$ mmol), and Solvable were purchased from New England Nuclear (Boston, MA). Flunitrazepam and clonazepam were gifts from Hoffmann-La Roche (Nutley, NJ). Lorazepam was a gift from Wyeth (Radnor, PA). PK11195 and Ro5-4864 were obtained from Research Biochemicals (Natick, MA). All other reagents were obtained from standard commercial sources.

\section{Drug Administration}

Lorazepam ( $2 \mathrm{mg} / \mathrm{kg}$ per day; $6.23 \mathrm{mmol} / \mathrm{kg}$ per day), PK11195 (1 to $10 \mathrm{mg} / \mathrm{kg}$ per day; 2.79 to $27.9 \mathrm{mmol} / \mathrm{kg}$ per day) and Ro5-4864 (10 mg/kg per day; $32.8 \mathrm{mmol} / \mathrm{kg}$ per day) were administered by subcutaneously implanted osmotic pumps as previously reported (Miller et al. 1988a). The doses of lorazepam and PK11195 were based on prior studies (Miller et al. 1992). The study groups were lorazepam alone, PK11195 alone, Ro5-4864 alone, lorazepam plus PK11195, lorazepam plus Ro54864, and all three compounds. For lorazepam and PK11195 and for all three compounds, drugs were administered via the same pump. In all cases, pumps were removed after 7 days of administration. All drugs were dissolved in PEG 400. Mice were studied at days 1, 4, and 7 after lorazepam discontinuation. As previously reported, concurrent administration of PK11195 does not alter lorazepam concentrations in brain (Miller et al. 1992). Also as previously reported (Miller et al. 1988a), lorazepam is undetectable in cortex at day 1 post. discontinuation and subsequently thereafter.

\section{Pentylenetetrazole-Induced Seizures}

As previously described (Schatzki et al. 1989), unrestrained mice were infused intravenously with a solu. tion of penytlenetetrazole, $7.5 \mathrm{mg} / \mathrm{ml}(5.43 \mathrm{mmol} / \mathrm{ml})$, at $0.30 \mathrm{ml} / \mathrm{min}$. Infusion was terminated at the onset of a tonic-clonic seizure as determined by two observers.

\section{Benzodiazepine Binding}

Benzodiazepine binding in vivo was performed as previously described (Miller et al. 1988a). Briefly, mice were injected intravenously with $3 \mu \mathrm{Ci}\left[{ }^{3} \mathrm{H}\right] \mathrm{Ro} 15-1788$. Af ter 20 minutes, animals were sacrificed and brains rapidly removed and dissected on ice. After weighing, brain regions were dissolved in Solvable $\left(40^{\circ} \mathrm{C}\right.$ for 24 hours) and then counted by scintillation spectrometry. For nonspecific binding, mice were treated with clonazepam, $5 \mathrm{mg} / \mathrm{kg}(16.13 \mathrm{mmol} / \mathrm{kg})$ intraperitoneally 30 minutes prior to radioligand injection and samples were processed as above.

For benzodiazepine binding in vitro, synaptosomal membranes from mouse cerebral cortex were prepared and binding was performed as previously described (Miller et al. 1988a). Briefly, [ $\left.{ }^{3} \mathrm{H}\right] \mathrm{FNTZ}$ at 0.1 to 10 $\mathrm{nmol} / \mathrm{L}$ was added to duplicate or triplicate samples. Flunitrazepam at $10^{-5} \mathrm{~mol} / \mathrm{L}$ was added to an identical set of samples. After incubation at $4^{\circ} \mathrm{C}$ for 45 minutes, samples were filtered using a Brandel M48R (Gaithersburg, MD) onto Whatman GF/B filters. Filters were washed three times with cold buffer and counted by scintillation spectrometry.

\section{Data Analysis}

Binding data were analyzed using the EBDA programs (McPherson 1983). Data were compared using analysis of variance with Dunnett's test or Student's $t$-test.

\section{RESULTS}

\section{Pentylenetetrazole-Induced Seizures}

At 1 day postdiscontinuation, there was no difference between mice treated with lorazepam or the combination of lorazepam and PK11195 (Fig. 1). However, at day 4 postdiscontinuation, seizure threshold was markedly decreased in mice treated with lorazepam 


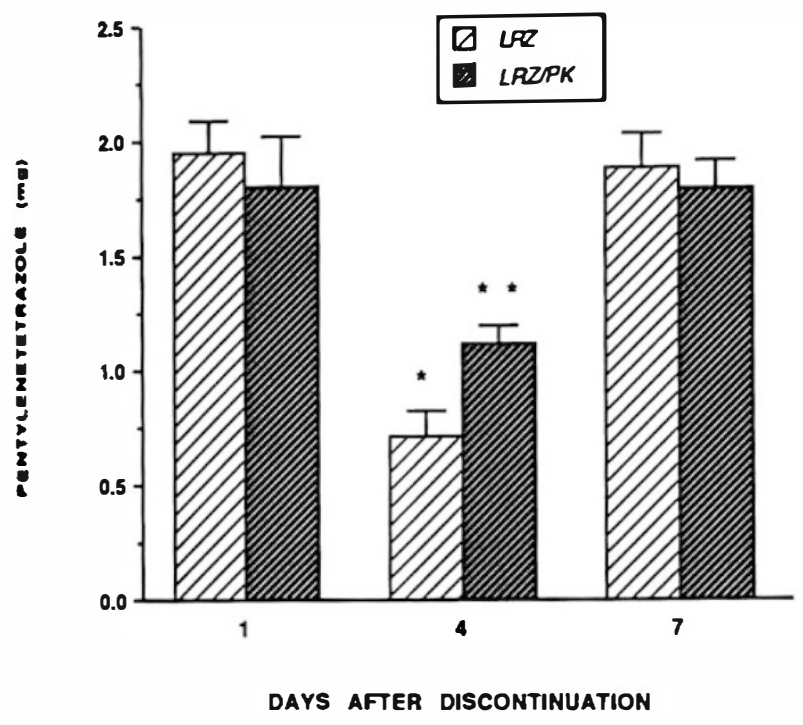

Figre 1. Pentylenetetrazole-induced seizures after lorazepam (LRZ) and PK11195 (PK). Mice treated with LRZ (2 mg/kg perday) or LRZ plus ( $5 \mathrm{mg} / \mathrm{kg}$ per day) for 7 days were evaluated at days 1, 4, and 7 postdiscontinuation. Unrestrained mice were injected intravenously with pentylenetetrazole, 7.5 $\mathrm{mg} / \mathrm{ml}$ at $0.30 \mathrm{ml} / \mathrm{min}$. Infusion was discontinued at the onset of a tonic-clonic seizure. Pentylenetetrazole = quantity required to induce a seizure. Results are mean $\pm \mathrm{SEM}, n=$ 6 109. $" p<.05$ compared to LRZ at days 1 and $7 ;{ }^{\star \star} ~ p<.05$ compared to LRZ/PK at days 1 and 7 , and to LRZ at day 4 .

alone as previously reported (Schatzki et al. 1989). Mice treated with both lorazepam and PK11195 had a signifcantly higher seizure threshold compared to brazepam alone, although the threshold for combined treatment remained reduced compared to day 1 . Results at day 7 postdiscontinuation were similar to day 1 and showed no differences between the two treatment groups. Seizure threshold in mice treated with PK11195 alone was similar to vehicle at days 1,4 , and 7 postdiscontinuation (data not shown).

To evaluate the dose-response effect of PK11195, two additional doses, 1 and $10 \mathrm{mg} / \mathrm{kg}$ per day, were administered in combination with lorazepam, and seizure thresholds were determined at 4 days postdiscontinuation (Fig. 2). Seizure threshold was not signifcantly altered by administration of PK11195 at 1 $\mathrm{mg} / \mathrm{kg}$ perday compared to lorazepam. As noted above, PK11195 at $5 \mathrm{mg} / \mathrm{kg}$ per day significantly reversed the effects of lorazepam discontinuation. Administration of PK11195 at $10 \mathrm{mg} / \mathrm{kg}$ per day demonstrated a further small, nonsignificant increase beyond the $5-\mathrm{mg} / \mathrm{kg}$ per day dose, andalso differed significantly from lorazepam alone. Pentylenetetrazole-induced seizure thresholds were not altered by PK11195 alone at 1 and 10 mg/kg per day.

To evaluate the specificity of PK11195 in altering lorazepam discontinuation effects, mice were treated

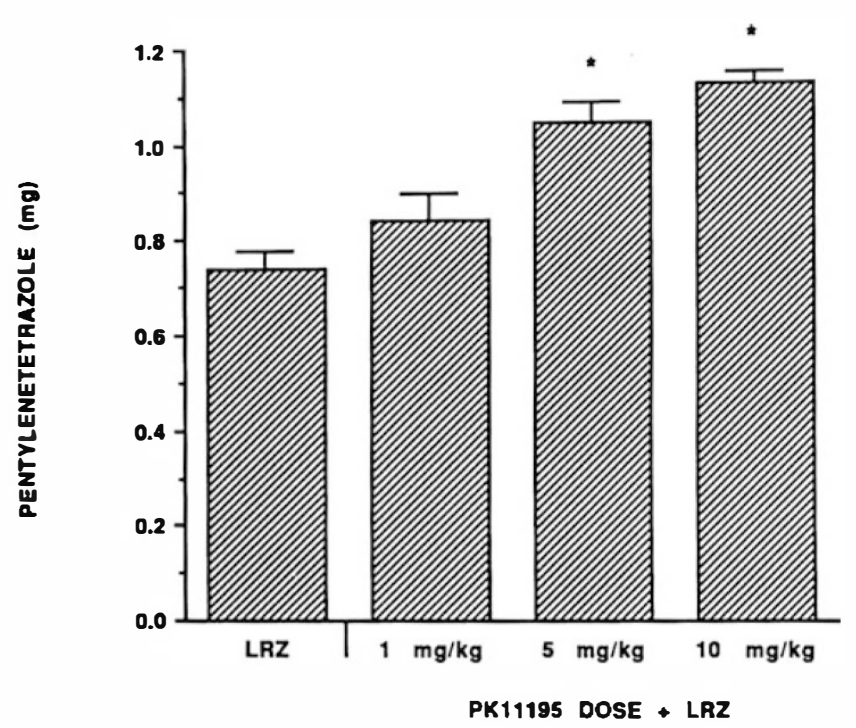

Figure 2. Dose effects of PK1195 (PK) in combination with lorazepam (LRZ). Mice treated with LRZ ( $2 \mathrm{mg} / \mathrm{kg}$ per day) or LRZ plus PK ( 1 to $10 \mathrm{mg} / \mathrm{kg}$ per day) for 7 days were evaluated at day 4 postdiscontinuation. Unrestrained mice were injected intravenously with pentylenetetrazole, $7.5 \mathrm{mg} / \mathrm{ml}$ at $0.30 \mathrm{ml} / \mathrm{min}$. Infusion was discontinued at the onset of a tonic-clonic seizure. Results are mean $\pm \mathrm{SEM}, n=6$ to 13 . ${ }^{*} p<.05$ for PK 5 and $10 \mathrm{mg} / \mathrm{kg}$ compared to LRZ.

concurrently with Ro5-4864, which competes with PK11195 for similar sites, and evaluated at 4 days postdiscontinuation (Fig. 3). Administration of Ro5-4864, $10 \mathrm{mg} / \mathrm{kg}$ per day, in combination with lorazepam was not significantly different from lorazepam alone when seizure threshold was evaluated at 4 days after lorazepam discontinuation. Similarly, when Ro5-4864 was coadministered with PK11195 and lorazepam, thresholds were unchanged from lorazepam alone, and significantly different from the combination of PK11195, $5 \mathrm{mg} / \mathrm{kg}$ per day, and lorazepam.

\section{Benzodiazepine Binding In Vivo}

As previously reported, benzodiazepine binding in the cortex and hippocampus was similar at 1 and 7 days after lorazepam discontinuation, but was increased significantly at 4 days compared to 1 and 7 days after drug discontinuation (Figure 4; Miller et al. 1988b). Similar results were observed in the cortex in animals treated with the combination of lorazepam and PK11195 at 5 $\mathrm{mg} / \mathrm{kg}$ per day. In the hippocampus, however, concurrent administration of lorazepam and PK11195 led to significantly reduced binding at day 4 postdiscontinuation compared to lorazepam alone. There were no significant changes in binding in any group in hypothalamus, cerebellum, or pons-medulla (data not shown). In mice treated with PK11195 alone, binding 


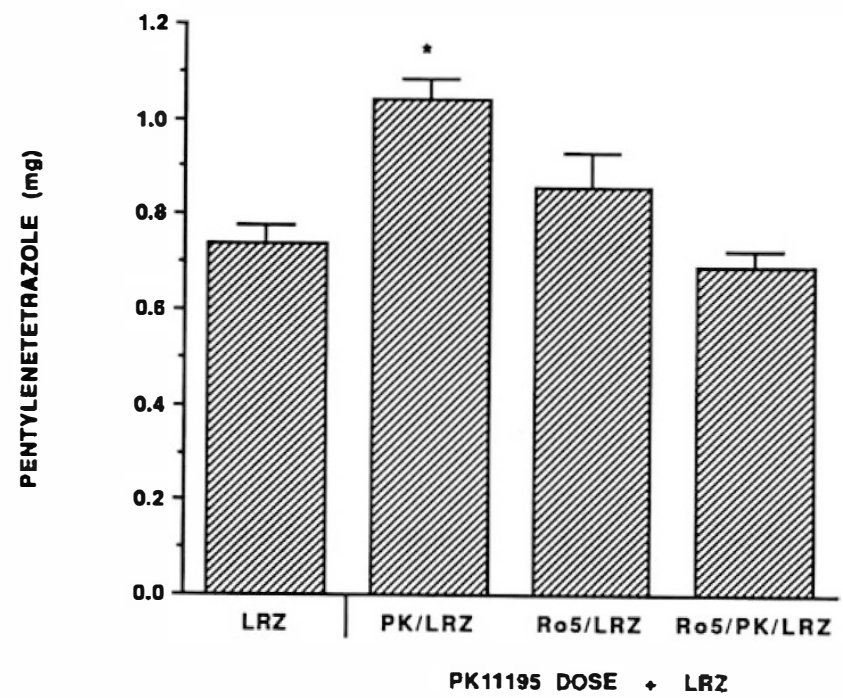

Figure 3. Effects of Ro5-4864 (Ro5) and PK11195 (PK) in combination with lorazepam (LRZ). Mice treated with LRZ (2 $\mathrm{mg} / \mathrm{kg}$ per day), LRX plus PK (5 mg/kg per day) or Ro5 (10 $\mathrm{mg} / \mathrm{kg}$ per day), or all three drugs for 7 days were evaluated at day 4 postdiscontinuation. Unrestrained mice were injected intravenously with pentylenetetrazole, $7.5 \mathrm{mg} / \mathrm{ml}$ at 0.30 $\mathrm{ml} / \mathrm{min}$. Infusion was discontinued at the onset of a tonic-clonic seizure. Results are mean $\pm \mathrm{SEM}, n=7$ to 13 . ${ }^{\star} p<.05$ for PK/LRZ compared to LRZ.

was unchanged at 1,4 , and 7 days after lorazepam discontinuation (data not shown).

\section{Benzodiazepine Binding In Vitro}

In cortical synaptosomal membranes, benzodiazepine receptor density was increased, but not significantly, at day 4 compared to days 1 and 7 after lorazepam or
Table 1. Benzodiazepine Receptor Density in Cortex In Vitro

\begin{tabular}{lccc}
\hline & \multicolumn{4}{c}{ Days after Discontinuation } \\
\cline { 2 - 4 } & $\mathbf{1}$ & $\mathbf{4}$ & $\mathbf{7}$ \\
\hline Lorazepam & $0.97 \pm 0.09$ & $1.33 \pm 0.21$ & $1.05 \pm 0.12$ \\
PK11195 & $1.18 \pm 0.23$ & $1.24 \pm 0.19$ & $1.14 \pm 0.21$ \\
PK/LRZ & $1.06 \pm 0.11$ & $1.37 \pm 0.20$ & $1.15 \pm 0.17$ \\
\hline
\end{tabular}

Binding was performed in mice treated with lorazepam (LRZ; 2 $\mathrm{mg} / \mathrm{kg}$ per day), PK11195 (PK, $5 \mathrm{mg} / \mathrm{kg}$ per day), or the combina tion (PK/LRZ) for 1, 4 and 7 days. Binding was performed in cortical synaptosomal membranes (P2) using $\left[{ }^{3} \mathrm{H}\right]$ flunitrazepam. Resuls are mean $\pm \mathrm{SEM}$ in pmol/mg protein, $n=3$ to 4 membranes at each point. Comparisons were performed using analysis of variance for each treatment group across the discontinuation period. There are no significant differences.

the combination of lorazepam and PK11195 (Table 1) Receptor density was unchanged at 1,4 , and 7 days after PK11195 alone. Apparent affinity at the receptor site was unaffected in any group evaluated (data not shown).

\section{DISCUSSION}

These results indicate that concurrent administration of PK11195 and lorazepam markedly attenuated, but did not totally eliminate, the effects of lorazepam dis. continuation both on seizure threshold and receptor up. regulation. Specifically, pentylenetetrazole-induced seizure threshold was decreased after lorazepam dis. continuation, as previously reported (Schatzki et al. 1989), but this effect was attenuated after concurrent PK11195 treatment compared to lorazepam alone. This

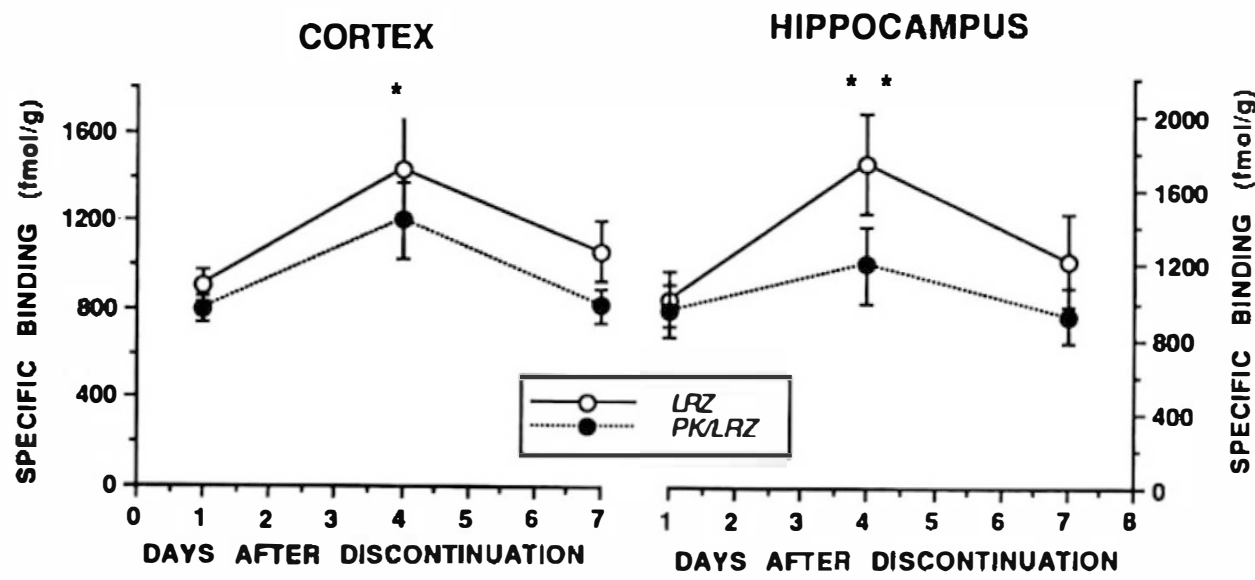

Figure 4. Benzodiazepine binding in vivo after lorazepam (LRZ) and PK11195 (PK). Mice treated with LRZ (2 mg/kg per day) alone or in combination with PK $(5 \mathrm{mg} / \mathrm{kg}$ per day) for 7 days were evaluated at days 1,4 , and 7 postdiscontinuation Benzodiazepine binding was determined by specific uptake of $\left[{ }^{3} \mathrm{H}\right]$ flumazenil. Results are mean \pm SEM, $n=5$ to 9 . ${ }^{\star} p<$ .05 for both LRZ and PK/LRZ compared to days 1 and $7 .{ }^{\star \star} p<.05$ for LRZ compared to days 1 and 7 and to PK/LRZ day 4 . 
effect was incomplete, since seizure thresholds remained reduced compared to day 1 after coadministration of PK11195. Also as previously reported (Miller et a. 1988b), benzodiazepine receptor binding increased in the cortex and hippocampus at day 4 following brazepam discontinuation. Concurrent treatment with PK11195 showed similar results in the cortex, but in hippocampus, there was a small, nonsignificant increase in binding at day 4 .

In addition, there appeared to be a dose-response effect, since a lower dose of PK11195, $1 \mathrm{mg} / \mathrm{kg}$ per day, did not alter lorazepam-induced threshold reductions at day 4. Conversely, a higher dose of PK11195, 10 $\mathrm{mg} / \mathrm{kg}$ per day, exerted a small, nonsignificant increment compared to the $5 \mathrm{mg} / \mathrm{kg}$ per day, suggesting that the maximal effect of PK11195 had been reached at 5 $\mathrm{mg} / \mathrm{kgper}$ day. Finally, the effect of PK11195 appeared to be site specific. The compound Ro5-4864, which competes with PK11195 at the peripheral benzodiazepine site (Basile et al. 1989) and the putative chloride channel site (Gee 1987), blocked the effects of PK11195 at a dose twice that of PK11195. This compound in combination with lorazepam did not exert a significant effect, arguing in favor of pharmacologic specificity at these sites.

Data with regard to seizure thresholds in the present study corroborate prior data that indicate an association between lorazepam discontinuation, decreased seizure threshold, and $\mathrm{GABA}_{\mathrm{A}}$ receptor upregulation (Schatzki et al. 1989). Intuitively, it might be expected that receptor upregulation would be associated with an increase in seizure threshold. However, in view of the unknown nature of the networks involved in convulsant effects and the potential subtype-specific effects of $\mathrm{GABA}_{A}$ receptors, it is plausible that receptor upregulation may be linked to convulsant sensitivity. It should also be pointed out that changes in receptor binding may not always reflectchanges in receptor funcbion (Miller 1991).

Prior reports have addressed the effects of PK11195 on benzodiazepine-induced tolerance. In a behavioral study in rats, Massotti et al. (1990) reported that concurent administration of PK11195 prevented the development of tolerance. In a mouse model, we have previously demonstrated that tolerance and accompanying receptor downregulation are attenuated, but not completely prevented, by PK11195 administration (Miller et al. 1992). Taken together with the current results, these data suggest that PK11195 administration can attenuate both tolerance and discontinuation phenomena. In addition, these results support a relationship between tolerance and discontinuation, as has been postulated in a number of neurotransmitter receptor systems (Miller 1991).

The neurochemical data in this study and in a prior study of tolerance (Miller et al. 1992) support relatively region-specific effects of PK11195; that is, effects on both receptor downregulation during chronic exposure and receptor upregulation following discontinuation were observed in the hippocampus, but not significantly in the cortex. Similar relative specificity has been observed based on choice of benzodiazepine compounds; lorazepam affects both the cortex and hippocampus (Miller et al. 1988a,b), whereas alprazolam affects only the cortex (Miller et al. 1989; Lopez et al. 1990; Galpern et al. 1990). The mechanism for this regional specificity may be related to receptor subtype differences in these regions (Olsen and Tobin 1990). Evidence based on autoradiography and in situ hybridization studies suggests differential distribution of receptor subtypes and subunit messenger ribonucleic acids, although the functional consequences of these data are unknown. It should be pointed out that these changes in binding were observed based in in vivo binding techniques. Use of in vitro methods in the cortex revealed qualitatively similar changes but the differences were not significant. This incomplete correspondence between in vivo and in vitro binding has been reported previously in studies of benzodiazepine tolerance and dependence (Miller et al. 1988a, b, Miller et al. 1989; Lopez et al. 1990; Galpern et al. 1991a), and may reflect effects of tissue preparation and assay conditions (Miller et al. 1987).

The mechanism for the effects of PK11195 on benzodiazepine tolerance and dependence remains uncertain. This compound has been shown to bind with high affinity at the "peripheral-type" benzodiazepine receptor, which appears to be present on nonneuronal cells in brain and at low density on neurons (Olson et al. 1988; Backus et al. 1988; Basile et al. 1989). In several situations, including oxygen consumption (Hirsch et al. 1989; Larcher et al. 1989) and cell multiplication and differentiation (Wang et al. 1984; Bisserbe et al. 1986), PK11195 functions as an antagonist at this site. However, the effects of PK11195 at this site in the central nervous system are unknown. It has been hypothesized that PK11195 might modulate glial production of steroids, which in turn can exert effects on the neuronal $\mathrm{GABA}_{\mathrm{A}}$ receptor (Krueger 1991). Alternatively, PK11195 also binds to an incompletely characterized site at the chloride channel of the $\mathrm{GABA}_{\mathrm{A}}$ receptor (Gee 1987; Gee et al. 1988). The effects of PK11195 on tolerance and dependence could be mediated at this site.

As noted above, in both cases PK11195 competes with Ro5-4864 for binding and in most functional assays. For example, in some behavioral paradigms Ro54864 exhibits a benzodiazepine inverse agonist-like effect, reversed by PK11195 (File and Pellow 1983). In neurochemical slice studies, Ro5-4864 also had effects similar to inverse agonists, whereas PK11195 exerted the opposite effects (Simmonds 1985). Thus, it is likely that PK11195 and Ro5-4864 are competing ligands, but the blockade of PK11195 effects by Ro5-4864 in the pres- 
ent study does not differentiate between activity at the peripheral site or the apparent chloride channel site. It should also be pointed out that initial evidence based on transient complementary dioxyribonucleic acid expression methods indicates that in somecases, PK11195 may not antagonize Ro5-4864 (Puia et al. 1989). These data argue in favor of additional sites of action for Ro54864; such sites could be involved in the effects observed in this study.

In view of the problematic nature of benzodiazepine tolerance and dependence in clinical use, concurrent administration of PK11195 or similar compounds may have a role in drug discontinuation after chronic treatment with benzodiazepines. Additional studies of similar compounds may elucidate the mechanism of PK11195 effects.

\section{ACKNOWLEDGMENTS}

The authors thank Young Shim for assistance. This work was supported in part by Grants DA-05258, MH-47598, and H-34223 from the U.S. Public Health Service. Dr. Miller is the recipient of a Faculty Development Award in Clinical Pharmacology from the Pharmaceutical Manufacturers Association Foundation. Dr. Perkins was the recipient of the 1991 ACNP-Upjohn Minority Summer Student Research Fellowship Award.

\section{REFERENCES}

Backus KH, Kettenmann H, Schachner M (1988): Effect of benzodiazepines and pentobarbital on the GABA-induced depolarization in cultured astrocytes. Glia 1:132-140

Basile AS, Bolger GT, Lueddens HW, Skolnick P (1989): Electrophysiological actions of Ro5-4864 on cerebellar Purkinje neurons: Evidence for "peripheral" benzodiazepine receptor-mediated depression. J Pharmacol Exp Ther 248:463-469

Bisserbe JC, Patel J, Eskay RL (1986): Evidence that the peripheral-type benzodiazepine receptor ligand Ro5-4864 inhibits beta-endorphin release from AtT-20 cells by blockade of voltage-dependent calcium channels. J Neurochem 47:1419-1424

File SE, Pellow S (1983): RO5-4864, a ligand for benzodiazepine micromolar and peripheral binding sites: Antagonism and enhancement of behavioural effects. Psychopharmacology 80:166-170

Galpern WR, Miller LG, Greenblatt DJ, Shader RI (1990): Differential effects of chronic lorazepam and alprazolam on banzodiazepine binding and $G A B A_{A}$ receptor function. Br J Pharmacol 101:839-842

Galpern WR, Lumpkin M, Greenblatt DJ, Shader RI, Miller LG(1991a): Chronic benzodiazepine administration. VII. Behavioral tolerance and withdrawal and receptor alterations associated with clonazepam administration. Psychopharmacology 104:225-230

Galpern WR, Miller LG, Greenblatt DJ, Szabo GK, Browne TR, Shader RI (1991b): Chronic benozdiazepine adminis- tration. IX. Attenuation of alprazolam discontinuation effects by carbamazepine. Biochem Pharmacol 42:S99S104

Gee KW (1987): Phenylquinolines PK8165 and PK9084 allosterically modulate $\left[{ }^{35} \mathrm{~S}\right] \mathrm{t}$-butylbicyclophosphorothionate binding to a chloride ionophore in rat brain via a novel Ro5 4864 binding site. J Pharmacol Exp Ther 240:747-753

Gee KW, Bolger MB, Brinton RE, Coirini H, McEwen BS (1988): Steroid modulation of chloride ionophore in rat brain. J Pharmacol Exp Ther 246:803-812

Greenblatt DJ, Miller LG, Shader RI (1990): Benzodiazepine discontinuation syndromes. J Psychiatric Res 24 (Suppl 2):73-79

Hirsch JD, Beyer CF, Malkowitz L, Beer B, Blume AL (1989): Mitochondrial benzodiazepine receptors mediate inhibition of mitochondrial respiratory control. Mol Pharmacol 35:157-163

Krueger KK (1991): Peripheral-type benzodiazepine receptors: A second site of action for benzodiazepines. Neuropsychopharmacology 4:237-244

Larcher J-P, Vayssiere J-L, Le Marquer FJ, Cordeau LR, Keane PE, Bachy A, Gros F, Croizat BP (1989): Effects of peripheral benzodiazepines upon the oxygen consumption of neuroblastoma cells. Eur J Pharmacol 171:197-202

Lopez F, Miller LG, Greenblatt DJ, Chesley S, Schatzki A, Shader RI (1990): Chronic administration of benzodiazepines: V. Rapid onset of behavioral and neurochemical alterations after discontinuation of alprazolam. Neuropharmacology 29:237-241

Massotti M, Mele L, DeLuca C (1990): Involvement of the "peripheral" benzodiazepine receptor type omega 3 in the tolerance to the electroencephalographic effects of benzodiazepines in rats. Pharmacol Biochem Behav 35: 933-936

McPherson GA (1983): A practical computer-based approach to the analysis of radioligand binding experiments. Comput Prog Biomed 17:107-114

Miller LG (1991): Chronic benzodiazepine administration: From the patient to the gene. JClin Pharmacol 31:492-495

Miller LG, Greenblatt DJ, Barnhill JG, Shader RI (1988a): Chronic benzodiazepine administration. I. Tolerance is associated with benzodiazepine receptor downregulation and decreased $\gamma$-aminobutyric acid $\mathrm{A}$ receptor function. J Pharmacol Exp Ther 246:170-176

Miller LG, Greenblatt DJ, Summer WR, Shader RI (1988b): Chronic benzodiazepine administration: II. Discontinuation syndrome is associated with upregulation of $\gamma$-aminobutyric $\operatorname{acid}_{A}$ receptor complex binding and function. J Pharmacol Exp Ther 246:177-182

Miller LG, Galpern WR, Byrnes JJ, Greenblatt DJ, Shader RI (1992): Chronic benzodiazepine administration. X. Concurrent administration of the peripheralligand PK11195 attenuates chronic effects of lorazepam. J Pharmacol Exp Ther 261:285-289

Olsen RW, Tobin AJ (1990): Molecular biology of GABAA receptors. FASEB J 4:1469-1480

Olson JMM, Cilix BJ, Mancini WR, Young AB (1988): Presence of peripheral-type benzodiazepine binding sites on human erythrocyte membranes. Eur J Pharmacol 152: 47-53 
Puia G, Santi MR, Vicini S, Pritchett DB, Seeburg PH, Costa $E$ (1989): Differences in the negative allosteric modulation of $\gamma$-aminbutyric acid receptors elicited by 4 '-chlorodiazepam and by a $\beta$-carboline-3-carboxylate ester: A study with natural and reconstituted receptors. Proc Natl Acad Sci USA 86:7275-7279

Schatzki A, Lopez F, Greenblatt DJ, Shader RI, Miller LG (1989): Lorazepam discontinuation promotes "inverse agonist" effects of benzodiazepines. Br J Pharmacol 98:451-454
Simmonds MA (1985): Antagonism of flurazepam and other effects of Ro15-1788, PK8165 and Ro5-4864 on the $\mathrm{GABA}_{\mathrm{A}}$ receptor complex in rat cuneate nucleus. Eur J Pharmacol 117:51-60

Weissman BA, Cott J, Hommer D, Paul SM, Skolnick P(1984): Electrophysiological and pharmacological actions of the convulsant benzodiazepine Ro5-4864. Eur J Pharmacol 97:257-261 